\title{
AMONGST WISHES AND POSSIBILITIES: EATING HABITS OF PREGNANT WOMEN FROM AN URBAN COMMUNITY IN SOUTHERN BRAZIL ${ }^{1}$
}

\author{
Carolina Frescura Junges², Lúcia Beatriz Ressel ${ }^{3}$, Marisa Monticellit
}

\footnotetext{
${ }^{1}$ Article extracted from the dissertation - Influência da cultura no comportamento alimentar de gestantes: contribuições para a enfermagem, submitted to the Nursing Graduate Program of the Federal University of Santa Maria (UFSM), in 2010.

${ }^{2}$ Doctoral student of the Nursing Graduate Program (PEN) of the Federal University of Santa Catarina (UFSC). Nurse at the University Hospital of UFSC. Santa Catarina, Brazil. E-mail: cfjunges@gmail.com

${ }^{3}$ Ph.D. in Nursing. Associate Professor at the Nursing Department and the Nursing Graduate Program of UFSM. Rio Grande do Sul, Brazil. E-mail: lbressel208@yahoo.com.br

${ }^{4}$ Ph.D. in Nursing. Associate Professor at the Nursing Department and the PEN/UFSC. Santa Catarina, Brazil. E-mail: marisa@ ccs.ufsc.br
}

\begin{abstract}
This qualitative study had the aim to understand the eating habits of pregnant women living in an urban community in southern Brazil. The method adopted was the ethnonursing approach and data were collected by means of the qualifying guide Observation-Participation-Reflection, with four pregnant women. The ethnographic analysis was conducted along with data collection, in the search for topics to support the research questions. The results led to the unveiling of cultural meanings that pregnant women attribute to knowledge and to their eating habits, and the influence of family history and social relations in the community stand out in this aspect. The perception of body changes, from the perspective of pregnant women, is related to their eating habit choices. By appreciating the cultural dimensions of care, nurses who assist pregnant women get close to the family and the community, allowing for better compliance with prenatal care by means of educational activities consistent with the culture of these pregnant women.
\end{abstract}

KEYWORDS: Prenatal care. Feeding. Women's health. Nursing. Culture.

\section{ENTRE DESEJOS E POSSIBILIDADES: PRÁTICAS ALIMENTARES DE GESTANTES EM UMA COMUNIDADE URBANA NO SUL DO BRASIL}

RESUMO: Trata-se de estudo qualitativo, que teve como objetivo compreender as práticas alimentares de gestantes moradoras de uma comunidade urbana no Sul do Brasil. O método adotou a abordagem da Etnoenfermagem e a coleta de dados foi realizada por meio do guia habilitador Observação-Participação-Reflexão, com quatro gestantes. A análise etnográfica foi feita em concomitância com a coleta de dados, buscando-se temas que sustentassem as interrogações da pesquisa. Os resultados permitiram o desvelamento dos significados culturais que as gestantes atribuem aos saberes e às práticas alimentares, sendo destacadas as influências da história familiar e as relações sociais existentes na comunidade. A percepção das mudanças corporais, sob a ótica das gestantes, está relacionada às suas escolhas alimentares. Os profissionais enfermeiros que assistem as gestantes, ao valorizarem as dimensões do cuidado cultural, aproximam-se da família e da comunidade, permitindo uma melhor adesão ao pré-natal, promovendo ações educativas coerentes com a cultura dessas gestantes.

PALAVRAS CHAVE: Cuidado pré-natal. Alimentação. Saúde da mulher. Enfermagem. Cultura.

\section{ENTRE DESEOS Y POSIBILIDADES: PRÁCTICAS ALIMENTARIAS DE EMBARAZADAS EN UNA COMUNIDAD URBANA DEL SUR DE BRASIL}

RESUMEN: estudio cualitativo, cuyo objetivo fue comprender las prácticas alimentarias de embarazadas que viven en una comunidad urbana al sur de Brasil. El método adoptó el abordaje de la etnoenfermería y la recolección de datos ocurrió a partir de un guión habilitador Observación-Participación-Reflexión, con cuatro embarazadas. El análisis etnográfico fue realizado en concomitancia con la recolección de datos, buscando temas que mantuvieran las interrogaciones de investigación. Los resultados permitieron revelar los significados culturales que las embarazadas atribuyeron a los saberes y a las prácticas alimentares, destacando las influencias de historia familiar y las relaciones sociales existentes en la comunidad. La percepción de los cambios corporales bajo la óptica de las embarazadas está relacionada a las elecciones alimentarias. Los profesionales enfermeros que ayuden a las embarazadas, al valorar las dimensiones del cuidado cultural, se aproximan de la familia y la comunidad, permitiendo una mejor adhesión al pre natal y promocionando acciones educativas coherentes con la cultura de estas gestantes.

PALABRAS CLAVE: Atención prenatal. Alimentación. Salud de la mujer. Enfermería. Cultura. 


\section{INTRODUCTION}

Cultural representations attach certain values that correspond to practices and ideas accepted in certain social groups. This means that, historically, the human behavior is built by the social actors themselves. This process is continuous and unfinished, as human relations are uninterrupted and permanently renewed..$^{1-5}$

The network of symbols and meanings that the individuals build in order to shape life and take action on it are thus the result of the dynamics experienced in these interrelations. This particular network, always mutable, public and internalized, will guide the praxis of daily life. Therefore, it has a dual feature: it is fed, on one hand, by collective values and practices and, on the other hand, by the individual's subjectivity that, from the experience with a group or different groups will interpret, in a dynamic way, the phenomena and events of life, by creating rituals, symbols and peculiar representations. ${ }^{1}$

The symbols that are part of a culture are means of dissemination and thus they provide the intellectual ingredient to the social process. The symbolic conceptions encompass elements that describe how the world is, and also provide guidelines on how to act, and models of what individuals see as behavior standards. ${ }^{1}$

From this point of view, ethnographers have proved that, in all societies, eating habits are endowed with symbolic features that define a group. Eating must then be acknowledged and studied by means of the analysis of social and cultural aspects. Anthropologists analyze this practice and indicate that different social groups have different performances regarding eating habits. Each culture has a different set of implicit rules that determine who prepares the food, who serves it, which individuals or groups can share a meal, and where and when a certain eating practice can take place. ${ }^{2}$

Some of the current definitions, used in scientific productions, emphasize eating from a biological and nutritional point of view. Nevertheless, it is necessary to study the sociocultural aspects, as they will define the preferences and eating habits of individuals. ${ }^{2-3}$ Human nutrition, besides being a biological phenomenon, is also a set of practices learned and taught both in family and social contexts. ${ }^{3}$ As important as the measurement of calories and the analysis of nutritional values, the understanding of symbols and eating rituals allow the interpretation of the culture of a group and therefore the identification of the elements that influence eating choices.

The diet of certain groups always raises questions, praises intergenerational teachings and plays key roles in scientific studies. In our study, the investigative concern is focused on eating habits of pregnant women. This choice will send us to body and digestive changes that occur during pregnancy, but also to a set of symbols and meanings that lead women to choose or prefer certain foods rather than others.

In this sense, the professional and scientific interest is aimed at the understanding of elements that are part of eating habits and the effects on the pregnancy evolution. Prenatal care leads pregnant women to identify the characteristics of their eating habits and thus to reorganize or keep them. In this context, the prenatal nurse can bring together the scientific knowledge and the one that comes from the social environment of the pregnant women.

Popular knowledge related to eating habits of pregnant women play an important role in care given within the family environment, aiming to preserve the mother and child's health. Nevertheless, not all the taboos and eating restrictions related to pregnant women can be explained this way, as vulnerability does not refer only to the physiological conditions but also to a social ambiguity. ${ }^{4}$ The woman goes through a temporary space that takes her to a new social status, that of a mother, and this condition varies according to each culture, so the rituals and taboos around pregnancy, labor and postpartum also mark this transition. ${ }^{4-5}$

Based on the above, the objective of this study was to understand the eating habits of pregnant women living in an urban community in southern Brazil.

\section{METHOD}

This is a qualitative study and its methods consisted of researches with delimited groups and segments, as well as social stories, from the players' point of view. ${ }^{6}$ The methodological approach followed the principles of ethnonursing, ${ }^{7}$ as it is one of the most commonly used methods to collect data on the culture of a group. Through it, it is possible to understand facts, perceptions and other types of information that reveal the reality 
of people's lives. ${ }^{5-7}$ For this approach, observation is an essential tool.

The setting chosen for the research was the northern area of Santa Maria, a city located in the southern region of the state of Rio Grande do Sul. The places where data were collected were the nursing office (where prenatal appointments and pregnant group meetings take place), the Kennedy Health Unit (USK, as per its acronym in Portuguese) and the homes of the pregnant women. USK is a health unit where training and practical classes of the undergraduate nursing course of the Federal University of Santa Maria (UFSM, as per its acronym in Portuguese) take place and prenatal care is given by a nursing professor from the Nursing Department of the university. The researcher collected data during the appointments with the nursing professor, as well as during the pregnant group meetings, which were conducted by the same professional, and also by means of home visits that were previously scheduled with the pregnant women.

From the beginning of the research project, the researcher was inside USK, getting to know the local reality and its professionals. Afterwards, in the beginning of 2010, there was the first meeting with the prenatal nurse in order to enable data collection. The pregnant women who received prenatal care in USK were invited to take part in the study, based on two inclusion criteria. The first condition was the provision of prenatal care by a USK nurse in the first semester of 2010. And the second condition was that the pregnant woman should be in the first or second trimester of pregnancy, so the data collection would not be interrupted by labor.

The pregnant women who met these conditions were introduced to the researcher by the nurse in January and February. The observations began in March, with three women, but in April another woman, who began prenatal care in the second trimester of pregnancy and met the inclusion criteria, was invited to participate. This fourth participant helped to confirm the information already collected in the first month, as the reports of the other three women indicated important similarities.

As opposed to the quantitative study, the number of subjects is not a priority in the qualitative study, but rather the intensity of the relationship between the researcher, the participants and the study setting. ${ }^{6,8}$ There was saturation of data two months after the fourth participant joined the research, as the information, observations and reports obtained became increasingly repetitive. Therefore, the period of data collection lasted from March to May of 2010.

The technique used to collect data was the Observation-Participation-Reflection (O-P-R), which consists of a qualifying guide divided into four steps that help the researcher to enter gradually the environment where the subjects are found and remain in the "natural" context of the informants. ${ }^{7}$

In the first stage, the aim was to observe and listen to the informants and the initial contact with each one occurred during a nursing consultation. Throughout the consultation, the behavior of the pregnant women was observed, as well as the verbal and non-verbal interactions and other aspects that were relevant for description and recognition of the participants.

In the second stage, the observation continued to be the most important technique; however, the verbal interaction between the researcher and the pregnant women began to happen during the consultations. The observations started to happen also in the pregnant group meetings.

In the third stage, the researcher started gradually to participate more effectively in the activities carried out by the pregnant women, and observation was often secondary. Based on data obtained from previous observations, the researcher interviewed each pregnant woman, making the appointments more individual. This stage took place in their homes. There was a search for similarities and differences between the speeches delivered both in the consultations and in the group meetings and their social realities. The activities observed and carried out by the researcher were focused on the culinary environment and representations given to food and eating.

In the fourth stage, there were reflexive observations, where the events and information gathered were analyzed. At this stage, the records were retrieved and nutritional aspects were assessed, which could be better elucidated.

The field diary was used as instrument to record the observations and relevant data. The analysis of information occurred in four steps, simultaneously with the data collection process: collection and recording of raw data; identification 
of descriptors and components; analysis of context and pattern; identification of topics, relevant findings and theoretical formulations. ${ }^{7}$

In the first stage, the notes in the field diary were the basis for the elaboration of reports which contained a detailed description of the studied setting, cultural perceptions of pregnant women, the initial interpretation of the researcher concerning the material produced and records from authors that could foster discussion about the findings. In the second stage, the topics were organized. The identification of similarities and differences in the material produced led to a thematic classification, being the basis for the scripts of individual interviews that took place in the third stage of data collection. The third stage was characterized by the analysis of data obtained from observations made in the group meetings and in the women's homes, as well as from interviewees' reports. These data were inserted in the themes defined in the previous stage. Finally, in the next stage, the classified material was read again and there was a critical reflection about the information found and about findings from the literature, in order to build theoretical formulations and recommendations.

The research project was approved by the Municipal Department of Health of Santa Maria, and then by the Research Ethics Committee of UFSM, under certificate n. 0287.0.243.000-09. After clarifications about the importance of the research and also about its risks and benefits, the pregnant women invited to participate signed a Free and Informed Consent Form. It is worthy of note that their identities have been kept confidential, as nicknames were randomly chosen.

\section{RESULTS AND DISCUSSION}

The eating topic engaged a reflection among the participants concerning the gestational condition. For them, being pregnant meant accepting or not their physical, emotional and cultural changes as normal. They noted that the pregnancy was being lived as a "natural" process and with few changes: [...] I wasn't sick, I didn't experience such things. Now I feel more tired and have pain in my legs, but that's all. It's just like the first one, I'm just careful not to carry my son in my arms so as not to hurt my back (Maria); [...] a healthy pregnancy is the one that the woman is not sick very often. I myself wasn't much. It's a pregnancy that is not full of aversions, in which the pregnant is not so clingy. It's being able to do the household chores. To me, this is a healthy pregnancy. The only thing that bothers me is the backache (Vanessa); [...] I can tell you that I had no change. Just the breasts that became more sensitive. I even think that I work more [now]. Of course, we have to take some precautions, but everything remains normal (Luiza).

In these statements, we can clearly see that dispelling the stigma of disease defines the way pregnancy is seen. Pregnancy was analyzed as a process that is not related to health risks, but mainly to physiological changes, identified as tolerable discomforts to the pregnant women. On the one hand, this approach contributes to demedicalize the gestational process, which sends us to the current mobilization of the health professionals who work in the field of women's health. This effort fosters the humanization of prenatal care and brings women to the fore during the pregnancy and postpartum processes. Nevertheless, it is necessary to make sure that the mother-to-be understands the pregnancy is going well and with no significant changes, as this can be strengthened by the mother herself, and also by the media and health professionals. ${ }^{9}$

Despite the fact that the pregnant woman is highly affected by the normative speeches that turns her responsible for the protection of her body and the baby, the dissemination of concepts that praise the mother figure maximize the understanding, still in place, that motherhood represents the completeness of female nature. In other words, the social status that becomes clear, the body changes and the physiological changes that they are subject to during pregnancy, labor, the postpartum period and lactation are seen as normal by someone whose desire is becoming a reality. Thus, when pregnancy is accepted, all of its consequences are included in this acceptance. Therefore, a balanced behavior (not characterized by complaints or "whining") is expected from the woman experiencing a normal or low risk pregnancy. Such aspects have been detected in studies that discuss women's social role in the performance of motherhood, whether it is during pregnancy or during the later stages of life. . $^{4-5,10-11}$

Furthermore, it is possible to argue that the representations of motherhood resulting from public policies expand the possibilities of normal maternal behaviors, the ways to care and feel, which affect the mother-child relationship, what is "normal" and "natural". This understanding is 
closely related to the new politicization of motherhood. ${ }^{9}$ This classification expresses the individual responsibleness of women to give birth and raise healthy and balanced children, which is often their project of life. ${ }^{9}$

In line with these perceptions of pregnancy, the informants first noted the absence of significant changes in eating habits. Nevertheless, they admitted afterwards and throughout the survey that some adaptations were necessary, concerning the intake of some foods: [...] the pregnant woman must have an adequate diet, eat well, at the right times, not much junk food, have a diet high in proteins [...]. If the woman didn't have many options before, after she got pregnant, she has to eat more, not in quantity, but in variety, especially fruits and vegetables (Maria); [...] it is important to eat more fruit and vegetables. If she didn't eat much before getting pregnant, now she has to (Alice).

Eating at the right times and increasing or starting the intake of fruits and vegetables are seen as healthy practices for pregnant women. The focus on the intake of fruits, vegetables and greens (FVG) is associated with health and, indirectly, with the concept of nutritional risk. It is clear in the women's speeches that it is an idealized knowledge and a desired practice. Nevertheless, it was observed throughout the study that the intake of FVG is still low, for economical or cultural reasons.

According to the World Health Organization, the low intake of FVG is among the top 10 risk factors that contribute to mortality in the world. ${ }^{12} \mathrm{~A}$ diet focused on the intake of FVG helps to reduce the risks of cardiovascular diseases and cancer, and can also reduce the risk of obesity, diabetes and malignant neoplasms, especially gastrointestinal ones. ${ }^{12-13}$ Such scientific evidence has turned into initiatives of promotion of healthy diets, but the results show low rates of adherence from people to this new eating habit.

The risks to health, caused by an inadequate food intake, mentioned by health professionals and government bodies, is supported mainly by quantitative researches. Therefore, the content is delivered in numbers and in a unilateral way to lay people, through recommendations and eating prescriptions. A mere repetition of statements that foster the intake of FVG does not ensure the consent and acknowledgment of risk factors associated with an inadequate diet. It has been observed that it is necessary to provide new knowledge and give way to popular knowledge, valuing traditions and eating cultures. ${ }^{3,13}$

Another reported aspect was the increase in the number of meals and in food intake: [...] I've been to the fridge more often. I grab something to eat, I'm always chewing. And in the meal time, I've noticed that I'm eating more: two helpings, and sometimes, big ones [laugh]. It's because of pregnancy, I can't satisfy my hunger (Maria); [...] I've noticed that I'm eating more. I was hungrier in the beginning of pregnancy. I nibbled something every five minutes. Now that I'm in week 30, I eat less and am satisfied (Vanessa); [...] after I got pregnant, it's sacred, I have to have breakfast, which I didn't do before, and then, when it's $10 o^{\prime}$ clock, I have something to eat, otherwise, if I don't eat for a long time my stomach hurts. After I got pregnant I noticed this change (Luiza).

After the analysis of these statements, we see the adaptations of the mother to the new nutritional demands, especially new times for meals and the increase of food intake.

One of the pregnant women (Vanessa) reminds that in the beginning of her pregnancy, she noticed an increase in the number of meals, and later in the 30th week, there was a decrease in intake, which can be explained by the fact that the first trimester is a period of adaptations, both from a physiological and a cultural point of view. Another topic that is striking in these statements is the appearance of a "sacred" moment, a daily event (breakfast) that is ritualized by the pregnant. When she gets to know that she is pregnant, both the woman and her family try to acknowledge the presence of a fetus, as its movements cannot be felt yet and the belly is not protruding. One of the ways to feel closer to the baby is through eating, as the woman and the family allow the food excess that makes the fetus grow.

During pregnancy, the nutritional needs increase, as a result of metabolic adaptations and nutritional demands for the fetus growth. ${ }^{14}$ Digestive changes result in eating adaptations, both in the number of daily meals and the quantity taken. ${ }^{14}$ This information is present in prenatal care and can guide new eating practices.

From a cultural approach, we note a symbolic popular belief that the pregnant women must "eat for two". 3:76 Besides, not having the meals at the right times and refusing to have a healthy diet can be associated with women who have not accepted their pregnancy socially, which repre- 
sents a hidden desire to cripple it. Conversely, eating more and taking foods that are considered healthier by their social group reflects the image of an ideal mother that is concerned with her health and her child's. ${ }^{15}$

The wish to eat inedible foods was also present in these women's daily life. Throughout the interviews, even though they described it as strange or even "absurd", they confessed the desire for eating soap, bricks and lime with salt: [...] I can smell better than before, even things that had no smell. Recently, I was washing the dishes and felt like eating the soap, it was so weird. It was the smell that aroused the urge, but I didn't eat it. Yesterday I was telling my neighbor and she told me that when she was pregnant she had the urge to eat wax. She said she couldn't walk around the house because the smell of wax was everywhere. The urge was so strong that her mother-in-law told her to try just a little. Then she ate it, but she said it was no use because the urge was for the smell, she wanted to "eat the smell". Fortunately I didn't eat the soap, because I think the same would have happened to me [laugh] (Maria); [...] I wanted to eat the dust that came off the bricks. It was in the very beginning of pregnancy, but I already knew I was pregnant. I didn't eat, but I wanted to. I asked my mother-in-law, who said I had to eat because nothing is harmful for pregnant women. I was a little afraid it would be harmful so I didn't eat. Then, I had no longer this urge (Vanessa); [...] lime with salt [laugh], even for that I had the urge. I don't remember having this in my previous pregnancies. Because urges are just a fuss. But recently I looked at a lime and felt like sucking it. I ate it screwing up my face. But that was all, because I used to use it as a salad dressing, and that is absurd. Eating lime with salt? (Luiza).

The participants recalled the occurrence of urges, showing strangeness and doubts as they acknowledged this change. Besides, the greater olfactory sensitiveness of the pregnant women was pointed out as a possible triggering factor.

A worrying picture may surface, as the intake of inedible foods is supported by the family and the social network. This is evidenced when they search for help from their mother-in-law or their neighbors. The aforementioned people play an important role in the women's social life and they interfere in their choices. It is worth highlighting that the health professionals were not mentioned as a support to answer questions regarding this perceived change.
Maria thought it was reasonable not to eat soap and to have a second opinion. Vanessa did not eat the substance for fear of feeling sick, even though she was encouraged by her mother-in-law. This piece of advice was justified by the idea (accepted in that group) that "nothing is harmful for pregnant women". In Luiza's case, eating lime with salt was mentioned as absurd because it was not consumed before, despite being ingredients usually used for cooking.

The data show that the pregnant women feel embarrassed to talk about these urges and that health professionals seem not to be ready to acknowledge this problem in prenatal care. The cases go unnoticed and they can result in health problems for the mother and the child. The lack of dialog on this topic between professionals and the pregnant women, as well as the participation of relatives in prenatal care, make it difficult to find out this change, which prevents the establishment of a dialog with relevant guidance.

Pica is the term used mainly by health professionals to characterize the appetite for nonnutritive substances and atypical combinations of foods. ${ }^{16}$ Pica is not restricted to a geographical area, race, belief, culture or sex but is generally present in individuals with mental disorders, children and pregnant women. ${ }^{16-17}$ Its occurrence may be associated with anemia, constipation, abdominal distention, intestinal occlusion, dental problems, parasitic infections, toxoplasmosis, hypertensive syndromes, changes in lead absorption and hyperkalemia. ${ }^{16,18-19}$ Among the possible harmful effects for the fetus, we can mention premature birth, low birth weight, irritability of the newborn, reduced cephalic perimeter, exposure to chemical substances (lead, pesticides and others), all of which can increase the risk of perinatal death. ${ }^{16-17}$

Few studies describe the causes of eating urges during pregnancy. Taboos, superstitions, family history and economical conditions may interfere in the occurrence of pica, as well as emotional issues, especially the relief of stress and anxiety. ${ }^{16}$

According to the participants, the baby's health and weight depend on the mother's diet, therefore, it is essential to choose healthy foods: [...] I think my diet is important for my baby's weight gain, because they say it starts to gain more weight in the seventh month. I noticed this in my first preg- 
nancy, when I went to the hospital [...] In the hospital you have rules, the meals are scheduled, and you can't eat snacks, which I do here, so I noticed that it gained more weight (Maria); [...] the baby's health depends on my diet, because if I eat healthy stuff, it won't be harmful to him, but if you only eat junk food, it can be harmful, and I think my diet can have an effect on its weight, because I had an ultrasound, and now in my second pregnancy, the baby was weighing 1.215 $\mathrm{kg}$ after six months. I think it can be born too fat or too big (Vanessa); [...] all I eat the baby will eat as well, so if I eat something that will do no good, it will probably do no good to it either. So I try to eat healthy stuff, with vitamins, otherwise it can be born with some kind of abnormality (Luiza).

It is possible to identify in these speeches the presence of practices and medical vocabulary and the association of the hospital environment with the guarantee of an adequate diet. The medical culture pervades the statements, denoting it as an unquestionable knowledge and to some extent approachable to pregnant women. Furthermore, apart from the technological resources available in the prenatal care, the obstetric ultrasound appears to be the preferred one, both because the mother can feel closer to her baby and because of the idea of personification and measuring of the baby, especially the weight. Based on the information found in the examination report, the baby's weight is the major concern, after the identification of the sex. First, because it is a piece of information praised by the health professionals themselves, and then because it is easy to understand. Such evidence was confirmed by the statements of the participants of this study.

The fetus weight depends on a number of factors and can even be associated with the vascularization of the placenta, the length of pregnancy and other maternal features, in addition to the normal gain of weight during pregnancy. ${ }^{20}$ Despite the fact that this technical knowledge is not accessible to pregnant women, it is possible to identify that other technical elements are praised in prenatal care. In prenatal speeches, the attention that pregnant women must have with their diet is highlighted, as it can have harmful effects on the baby's weight and health. Such evidence can be seen through technological resources, like ultrasonography. Once again, the selfless ideology of preserving the mother's love plays an important role in prenatal care.
Nevertheless, it is essential to analyze the importance of technical practices that take place in prenatal care, with a critical and responsible look. The monitoring of the mother's weight can be done by means of the body mass index and the comparison with standards established by the Ministry of Health. ${ }^{14}$ Moreover, fetal growth can be assessed by measuring the fundal height and performing ultrasonography. ${ }^{14}$ Studies in the field of health sciences prove that malnourished women with deficient intake have greater possibilities to develop fetal risks such as low birth weight, intrauterine growth restriction, as well as higher risk of preterm birth and perinatal mortality. ${ }^{14,20-21}$ In the case of obese or overweight pregnant women, the risks are related to stillbirth, congenital malformation, especially in the neural tube, and macrosomia. ${ }^{22}$

\section{CONCLUSION}

It is evident that pregnant women associate the changes in eating habits with general changes expected for pregnancy. Nevertheless, they also note that eating is composed by elements that go beyond pregnancy and concern their previous history and the culture of the social group they belong, in which the family dictates the acceptable symbols and practices in that context.

Despite the fact that the initial statements from the participants indicate that pregnancy and diet were not related to new practices, afterwards they highlighted the need for adaptations, which were strongly recommended in the social context where they experienced pregnancy, that is, family and neighborhood relationships. The increase in the number of meals, in food intake and the better quality of food are elements highlighted by all participants, with the choice for a healthier diet being an expected practice for the pregnant woman. Another important element is the urge for substances considered by the participants themselves as "non-food". This topic revealed feelings of embarrassment and strangeness, and sometimes were associated with urges that needed to be satisfied. The importance given to a healthy diet, regarding its influence on the birth weight, is another topic which they considered relevant. The maternal practices in the choice of healthier foods, from a nutritional and cultural point of view, is often related mainly to keeping fetal weight within normal standards, which is done with ultrasonography examinations and after labor. 
As this study has an anthropological scope and was carried out in an urban community, many aspects observed in the daily life that were not directly related to eating habits of the pregnant women were essential to unveil the social context where they experienced their eating habits. The choice for the ethnographic model turned out to be necessary to understand the social context where the participants lived in and interpreted their ways of life. Thus, despite the fact that ethnography includes general aspects of living and provides a great amount of material for analysis, it also surprises the researcher, as it is only after observation of the local setting that it is possible to understand in detail the desired approach. In this study, during the data analysis, the strong influence of history on knowledge and practices of pregnant women was a prominent factor. The investigative field chosen covered other nuances of the research in the nursing field, making it possible to complement information, particularly regarding nutrition and anthropology.

The present study is expected to promote and foster new approaches of eating habits, considering other aspects of prenatal care and valuing elements not worked by health professionals such as the participation of families and communities in the eating choices of pregnant women. During the planning of health education activities, carried out by prenatal nurses, the focus on nutrition must be shared with other professionals, such as the nutritionist and the physician, taking into account the common belief and searching for ways to bring it closer to scientific knowledge.

The knowledge produced by this study may support activities in the academic field, broadening and favoring the teaching practice in different settings of care. The cultural care can contribute to the nurse's academic education, as it allows for both the student and the school to transit through different levels of human experiences.

\section{REFERENCES}

1. Geertz C. A interpretação das culturas. Rio de Janeiro (RJ): LTC, 1989.

2. Langdon EJ, Wikk FB. Antropologia, saúde e doença: uma introdução ao conceito de cultura aplicado às ciências da saúde. Rev Latino-Am Enferm. 2010 Mai-Jun; 18(3):173-81.

3. Hernández JC, Arnáiz MG. Alimentación y cultura: perspectivas antropológicas. Barcelona (ES): Ariel, 2005.
4. Helman CG. Cultura, saúde e doença. $5^{\text {a }}$ ed. Porto Alegre (RS): Artmed, 2009.

5. Monticelli M, Elsen I. A cultura como obstáculo: percepções da enfermagem no cuidado às famílias em alojamento conjunto. Texto Contexto Enferm. 2006 Jan-Mar; 15(1):26-34.

6. Minayo MCS. O desafio do conhecimento: pesquisa qualitativa em saúde. $12^{\mathrm{a}}$ ed. São Paulo (SP): Hucitec, 2010.

7. Leininger M, McFarland M. Culture care diversity and universality: a worldwide nursing theory. New York (US): Jones and Bartlett's Publishers Inc., 2006.

8. Turato ER. Métodos qualitativos e quantitativos na área da saúde: definições, diferenças e seus objetos de pesquisa. Rev Saúde Pública. 2005 Jun; 39(3):507-14.

9. Meyer DE. Corpos maternos pobres. Processos educativos "de inclusão social" contemporâneos. In: Ribeiro PRC, Silva MRS, Goellner SV, organizadores. Corpo, Gênero e sexualidade: composições e desafios para a formação docente. Rio Grande (RS): FURG; 2009. p. 19-31.

10. Moliterno ACM, Borghi AC, Orlandi LHSF, Faustino RC, Serafim D, Carreira L. Processo de gestar e parir entre as mulheres Kaigang. Texto Contexto Enferm. 2013 Abr-Jun; 22(2):293-301.

11. Cha C, Kim E. Assessing the role of culture in Korean goose mothers' lives. J Transcult Nurs. 2013 Jan; 24(1):86-93.

12. World Health Organization. The world health report 2003. Shaping the future. Geneva (CH): WHO; 2003.

13. Gomes FS. Frutas, legumes e verduras: recomendações técnicas versus constructos sociais. Rev Nutr. 2007 Nov-Dez; 20(6):669-80.

14. Ministério da Saúde (BR). Secretaria de Atenção a Saúde. Departamento de Atenção Básica. Atenção ao pré-natal de baixo risco. Caderno de Atenção Básica, n. 32. Brasília (DF): MS; 2012.

15. Baião MR, Deslandes SF. Gravidez e comportamento alimentar em gestantes de uma comunidade urbana de baixa renda no Município do Rio de Janeiro, Brasil. Cad Saúde Pública. 2008 Nov; 24(11):2633-42.

16. Saunders C, Padilha PC, Líbera BD, Nogueira JL, Oliveira LM, Astulla A. Picamalácia: epidemiologia e associação com complicações na gravidez. Rev Bras Ginecol Obstet. 2009 Set; 31(9):440-6.

17. López LB, Soler CRO, Portela MLPM. La pica durante el embarazo: un transtorno frecuentemente subestimado. Arch Latinoam Nutr. 2004 Jan; 54(1):17-24.

18. Toker H, Ozdemir H, Ozan F, Turgut M, Goze F, Sencan M, et al. Dramatic oral findings belonging to a pica patient: a case reporte. Intern Dent J. 2009 Fev; 59(1):26-30.

19. Corbelt RW, Ryan C, Weinrich SP. Pica in pregnancy: does it affect pregnancy outcomes? MCN Am J Matern Child Nurs. 2003 Mai-Jun; 28(3):183-9. 
20. Amorim AR, Lacerda EMA, Kac G. Uso e interpretação dos indicadores antropométricos na avaliação do estado nutricional de gestantes. In: Kac G, Sichieri R, Gigante DP, organizadores. Epidemiologia nutricional. Rio de Janeiro (RJ): Atheneu, 2007. p. 31-48.

21. Padilha PC, Saunders C, Machado RCM, Silva CL,
Bull A, Sally EOF, et al. Associação entre o estado nutricional pré-gestacional e a predição do risco de intercorrências gestacionais. Rev Bras Ginecol Obstet. 2007 Out; 29(10):511-8.

22. Valle CP, Durce K, Ferreira CAS. Conseqüências fetais da obesidade gestacional. O mundo da Saúde, 2008 Out-Dez; 32(4):537-41. 